\title{
Object-based attention: A tutorial review
}

\author{
Zhe Chen
}

Published online: 7 June 2012

(C) Psychonomic Society, Inc. 2012

\begin{abstract}
This tutorial provides a selective review of research on object-based deployment of attention. It focuses primarily on behavioral studies with human observers. The tutorial is divided into five sections. It starts with an introduction to object-based attention and a description of the three commonly used experimental paradigms in objectbased attention research. These are followed by a review of a variety of manifestations of object effects and the factors that influence object segmentation. The final two sections are devoted to two key issues in object-based research: the mechanisms that give rise to the object effects and the role of space in object-based selection.
\end{abstract}

\section{Keywords Attention $\cdot$ Object-based $\cdot$ Tutorial review}

Visual perception is necessarily selective. A natural scene typically contains a vast amount of information. However, because of the limited processing capacity of the visual system at any given time, we cannot process everything simultaneously. Given this limitation, it is perhaps not surprising that the factors that influence visual attention and the

\section{Z. Chen $(\bowtie)$}

Department of Psychology, University of Canterbury, Private Bag 4800, Christchurch, New Zealand

e-mail: zhe.chen@canterbury.ac.nz mechanisms that underlie the unit of selection are among the most studied topics in modern psychology.

Until the early 1980s, it was generally believed that visual attention operated within a spatial reference frame. This view is perhaps best illustrated by the various metaphors that have been used to describe attention, with the most widely accepted ones being spotlight (B. A. Eriksen \& Eriksen, 1974; Hoffman \& Nelson, 1981; Posner, 1980; Posner, Snyder, \& Davidson, 1980), zoom-lens (C. W. Eriksen \& St. James, 1986; LaBerge, 1983), and gradients (Downing \& Pinker, 1985). Although these models of attention differed regarding their conceptions of the flexibility of attentional selection and the spread of attentional resources within a selected region of space, they all emphasized the spatial properties of attention. Attention was believed to select on the basis of space, and all stimuli within the selected region were thought to receive some degree of processing regardless of observers' behavioral goals.

Although there is little doubt that space plays an extremely important role in visual selection (for reviews, see Cave, in press; Cave \& Bichot, 1999; Lamy \& Tsal, 2001), by the early 1980s, it had become clear that space was not the only reference frame within which attention operated. Because objects often overlap in space in natural scenes and we seem to have little difficulty attending to a specific feature or object among irrelevant distractors, it makes intuitive sense that the unit of attentional selection may also be based on features and objects, in addition to space. 
This tutorial focuses on object-based selection. ${ }^{1}$ Although object is a commonly used word in everyday communication, the question of what an object is in visual perception turns out to be rather difficult to answer (Adelson \& Bergen, 1991; Duncan, 1984; Logan, 1996; Scholl, 2001). This is because what constitutes an object depends not only on the physical properties of a stimulus or a group of stimuli (Baylis \& Driver, 1992; Kimchi, Yeshurun, \& Cohen-Savranzky, 2007; Kramer \& Jacobson, 1991; Kramer \& Watson, 1996), but also on how we parse an image in accordance with our behavioral goals (Marr, 1982). For the purpose of this tutorial, I will follow previous researchers (e.g., Goldsmith, 1998; Kimchi et al., 2007) and define a perceptual object as the elements in the visual scene organized by one or more Gestalt grouping principles and/or uniform connectedness. Due to space constraints, I will focus my review of object-based attention primarily on behavioral research, with a very selective review of physiological, neuroimaging, and clinical studies when necessary. The tutorial starts with a description of object-based attentional selection and the three commonly used experimental paradigms in object-based attention research. They are followed by a review of the different manifestations of object effects, the factors that influence object-based deployment of attention, and the mechanisms that give rise to the object effects. In the final part of the tutorial, I review the literature on the role of space in object-based selection. For interested readers, an extensive bibliography can be found at the end of this article.

\section{Object-based attentional selection and three commonly used experimental paradigms}

Even in the heyday of the space-based view of attention, various researchers noted the effect of objects on selective

\footnotetext{
${ }^{1}$ Due to space constraints, the literature on feature-based attention is not included in this review. Feature-based attention refers to the enhanced sensitivity to a feature value (e.g., a specific orientation, color, or motion direction) similar to an attended feature value regardless of whether the former is at the attended location or belongs to the attended object (see Maunsell \& Treue, 2006, for a review). For example, Treue and MartínezTrujillo (1999; Martínez-Trujillo \& Treue, 2004) showed that attending to a specific motion direction at one location enhanced the gain of MT neurons selective to the attended direction even though the receptive fields of the affected neurons were in the opposite visual hemifield. In addition to motion, feature-based attention has been found in several other feature dimensions, including spatial frequency, orientation, and color, and the attentional effects have been demonstrated in both physiological and psychophysical studies (e.g., Arman, Ciaramitaro, \& Boynton, 2006; Liu, Larsson, \& Carrasco, 2007; Roelfsema, Khayat, \& Spekreijse, 2003; Rossi \& Paradiso, 1995; Sàenz, Buračas, \& Boynton, 2002, 2003; Shulman \& Wilson, 1987; White \& Carrasco, 2011). Although feature-based attentional effects can contribute to object-based effects and vice versa under certain experimental conditions, these two types of effects can be dissociated (see Wannig et al., 2011). Whereas feature-based attentional effects are not limited to a perceptual object or group, object-based attentional effects are confined to the attended object or perceptual group.
}

attention (e.g., Francolini \& Egeth, 1980; Kahneman \& Chajczyk, 1983; Kahneman \& Henik, 1981; Kahneman, Treisman, \& Burkell, 1983; Neisser \& Becklen, 1975). Neisser and Becklen reported that people who were required to perform an attention-demanding task concerning one of two superimposed visual scenes could become remarkably unaware of superthreshold events happening in the unattended scene. Kahneman and Henik (1981) also found that interference from a task-irrelevant feature of a stimulus was much larger when that feature belonged to an attended object, relative to an unattended object, despite the fact that the locations of these objects were unpredictable. Furthermore, when the task was to report as many items in a display as possible, participants tended to jointly report or jointly miss items that were in the same perceptual group. These results led to the proposal that objects affect the distribution of attention and that attending to one aspect of an object facilitates the processing of other aspects of the same object regardless of task relevancy (Kahneman \& Chajczyk, 1983; Kahneman \& Henik, 1981).

In 1984, John Duncan published a seminal study, which arguably marked the beginning of a conceptual change regarding the unit of selection in visual attention. In several experiments, Duncan explored the limits of attention by measuring the number of objects that could be selected simultaneously without a cost. Observers saw stimulus displays that consisted of a bar superimposed on a box (see Fig. 1a). The bar was either dotted or dashed and was tilted to the left or right, and the box was either small or large and had a gap on the left or right side. The task was to make judgments about one or more of the objects' features. Observers reported one feature on one object (the bar or the box), two features on the same object, or two features on different objects. Relative to making only one judgment, they showed no decrease in accuracy when the second judgment was on the same object. However, their accuracy decreased when the second judgment was on a different object, demonstrating the limits of attending to two objects simultaneously. Since the bar and box overlapped in space, these results are difficult to explain in terms of spatial-based selection. However, they are consistent with the notion that attention selects the internal representation of an object (but see Watt, 1988, for an alternative interpretation) and that attending to one aspect of an object entails the processing of all the other aspects that belong to the same object. Similar one-object advantages have since been demonstrated in many studies, both when the primary dependent measure was accuracy (e.g., Kramer, Weber, \& Watson, 1997; Vecera \& Farah, 1994) and when it was response latencies (e.g., Baylis \& Driver, 1993; Behrmann, Zemel, \& Mozer, 1998; Chen, 2000).

In the 3 decades since Duncan's (1984) study, there has been an explosion of research on object-based selection (for 
Fig. 1 Sample displays from Duncan (1984), Egly, Driver, and Rafal (1994), and Kramer and Jacobson (1991). a Stimuli adapted from Duncan. The target display consisted of a bar superimposed on a box. The bar was either dotted or dashed and was tilted to the left or right. The box was small or large and had a gap on the left or right side. The task was to make judgment about one or two object features. Relative to making only one judgment, observers showed no decrease in accuracy when the second judgment was on the same object. However, their accuracy decreased when the second judgment was on a different object. b Stimuli adapted from Egly, Driver, and Rafal (1994). Observers saw displays that consisted of two rectangles. A precue indicated the most likely location of a subsequent target. On valid trials, the target would appear at the cued location. On invalid same-object trials, the target would appear at the uncued end of the cued rectangle. On invalid different-object trials, the target would appear at the uncued, equidistant end of the other rectangle. The location of the target is represented here by $\mathrm{V}$ for valid trials, IS for invalid same-object trials, and ID for invalid different-object trials. Responses were faster on valid than on invalid trials and on invalid same-object than on invalid different-object trials. c Stimuli adapted from Kramer and Jacobson (1991). The target, which was always at the center, was flanked by distractors that indicated either the same response or a different response. In the same-object condition, the three inner vertical lines and the two horizontal lines all had the same color, while the two outer vertical lines had a different color. In the differentobject condition, the central vertical line was in one color, while the other lines were in a different color. The figure on the left was an example of a same-object compatible trial. The figure on the right was an example of a different-object incompatible trial. Interference from distractors on incompatible trials was greater in the same-object condition than in the different-object condition

reviews, see Driver \& Baylis, 1998; Kanwisher \& Driver, 1992; Scholl, 2001). One study, which was conducted by Egly, Driver, and Rafal (1994), is of particular significance, for it introduced a paradigm that allowed the investigation of both space- and object-based deployment of attention within the same experiment. This paradigm has since become the most widely used paradigm in object-based attention research. In Egly, Driver, and Rafal, observers saw two rectangles presented side by side (see Fig. 1b). A spatial cue then appeared at one of the four ends of the rectangles, followed by a target at one of three locations: the cued location on $75 \%$ of the trials (the valid condition), the uncued end of the cued rectangle on $12.5 \%$ of the trials (the invalid same-object condition), and the uncued equidistant end of the other rectangle on the rest of the trials (the invalid different-object condition). The task was to detect the target as quickly as possible. Observers were faster to respond to the target at the cued location than at either of the uncued locations, indicating space-based attentional facilitation. Furthermore, they were also faster in the invalid same-object condition than in the invalid different-object condition. Since the spatial separation between the cue and the subsequent target was held constant in the latter two conditions, the differential reaction times (RTs) observed in these conditions suggest that attention spreads more quickly to other locations within the same object than between different objects (for alternative interpretations, see Lamy (a)

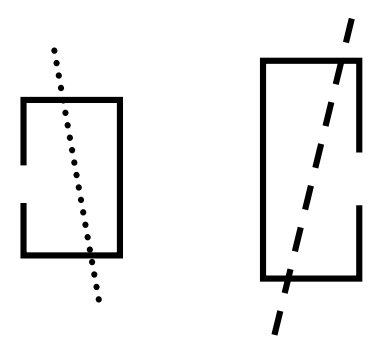

(b)

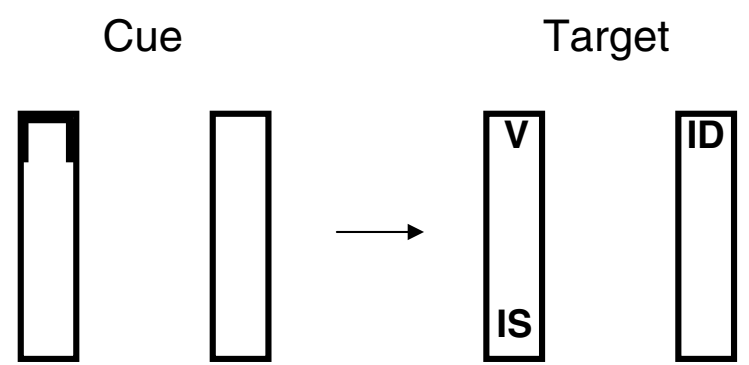

(c)

Same Object

\section{Different Object}

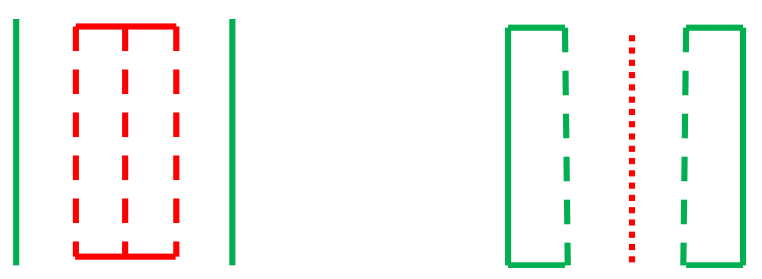

\& Egeth, 2002; Shomstein \& Yantis, 2002), indicating object-based deployment of attention. Using variants of Egly, Driver, and Rafal's two-rectangle paradigm, many researchers have replicated these findings. Regardless of whether the task required stimulus detection or identification, the shift of attention was faster within an object than between objects (e.g., Chen, 1998; Lavie \& Driver, 1996; Macquistan, 1997; Moore, Yantis, \& Vaughan, 1998; Pratt \& Sekuler, 2001).

A third paradigm commonly used in object-based attention research is the flanker interference paradigm (B. A. Eriksen \& Eriksen, 1974) with object manipulation. In this paradigm, a target is shown at a central location flanked by distractors that indicate either the same response as or a different response from that of the target (see Fig. 1c). On some trials (the same-object condition), the target and distractors belong to the same object or perceptual group. On the rest of the trials (the different-object condition), they belong to different objects or perceptual groups. Regardless of whether objects are defined on the basis of contours (e.g., 
Chen \& Cave, 2006; Richard, Lee, \& Vecera, 2008; but see Shomstein \& Yantis, 2002), Gestalt principles of color (e.g., Baylis \& Driver, 1992; Harms \& Bundesen, 1983; Kramer \& Jacobson, 1991), common motion (e.g., Driver \& Baylis, 1989; but see Berry \& Klein, 1993; Kramer, Tham, \& Yeh, 1991), connectedness (e.g., Kramer \& Jacobson, 1991), or good continuation (e.g., Baylis \& Driver, 1992), the general finding is that interference from distractors is greater in the same object/perceptual-grouping condition than in the different object/perceptual-grouping condition. In addition, when focal attention is prevented, observers are more likely to wrongly combine features from different objects when these objects are from the same perceptual group than when they are from different perceptual groups (e.g., Baylis, Driver, \& McLeod, 1992; Prinzmetal \& Keysar, 1989). Their ability to track independently moving targets in multiple-object tracking tasks (Pylyshyn \& Storm, 1988) is also impaired when the targets are merged to form objects such as lines, rubber bands, or Necker cubes (e.g., Scholl, Pylyshyn, \& Feldman, 2001). These results confirm that items that belong together are selected together.

\section{Other manifestations of object effects}

In addition to the findings described above and the paradigms that produced them, object-based attention has also been manifested in a variety of other ways via a number of other methods. Kahneman and Treisman (1984; Kahneman, Triesman, \& Gibbs, 1992) were among the first to explore object-based attention. Kahneman et al. (1992) used an object preview paradigm to investigate the relationship between object continuity and the efficiency of visual information processing. A typical trial consisted of a preview display with two or more letters, each in an individual frame, and a target display with a single letter in one of the frames. The task was to report the identity of the target letter. RTs to the target were reliably shorter when the target was a previewed letter that appeared in the same frame (absolute or relative), as compared with a previewed letter that appeared in a different frame. These results provide evidence for an object-specific preview advantage, which occurs when two objects in close spatiotemporal proximity are seen as different states of the same object relative to different objects.

Recently, Kimchi and her colleagues (Kimchi et al., 2007; Yeshurun, Kimchi, Sha'shoua, \& Carmel, 2009) reported that objects were also capable of capturing attention in a stimulus-driven matter by merely being objects. In several experiments, observers saw displays that consisted of multiple elements, a subset of which formed a perceptual unit (object) on some trials (object trials) and no perceptual unit on the other trials (no-object trials). The task was to report the color of a target, which was defined by its location relative to a cue (see Fig. 2). RTs to the target on the object trials were shorter when the cue appeared within the object and longer when the cue occurred outside the object. Because the object was not task relevant or associated with any abrupt onset (and was therefore free of luminance or motion transients), these results provide strong evidence for a unique property of objecthood: It can attract attention in a stimulus-driven manner even though the object has nothing to do with an observer's behavioral goals. They are also consistent with the findings in prior research that all else being equal, searching for a new object is more efficient than searching for an old object (e.g., Yantis \& Hillstrom, 1994; Yantis \& Jonides, 1996; but see also Franconeri, Hollingworth, \& Simons, 2005).

Several studies have explored the effect of object-based attention on saccadic eye movements. It was found that observers were more likely to make within-object, relative to between-object, eye movements when saccades were required for target identification (e.g., McCarley, Kramer, \& Peterson, 2002; Theeuwes \& Mathot, 2010), that the dwell time preceding the saccades was shorter when the switch of attention was within rather than between objects (e.g., McCarley et al., 2002), and that in memory recall tasks, participants' eyes were more likely to fixate on a location when that location was linked, rather than not linked, to an animated creature that presented the relevant information (e.g., Hoover \& Richardson, 2008).

Object-based attention also enhances manipulations in working memory. In Bao, Li, and Zhang (2007), participants were required to perform two tasks concurrently: to continuously monitor and update a target's location on the basis of incoming information and to count the number of times a second stimulus occurred. One group of observers (the separate group) were simply told to perform the two tasks, while the other group (the binding group) was encouraged to integrate the location and object occurrence information into a single object by imagining that the target was a digit 0 , which moved to a different location in accordance with incoming location information and which increased its value by 1 every time a second stimulus, whose frequency required monitoring, appeared. The results showed that RTs were longer in the separate group than in the binding group. Moreover, the cost of shifting attention between the location and object occurrence tasks was larger for the separate group than for the binding group, suggesting that binding information to a single object facilitates information manipulations in working memory. Related results were reported by Kahneman and Henik (1977, 1981), who manipulated the perceptual groupings of the stimuli that the participants had to recall and found a higher recall rate when the stimuli were displayed in the same perceptual group rather than in different perceptual groups. Ohyama and Watanabe (2010) 
Inside Object (A)

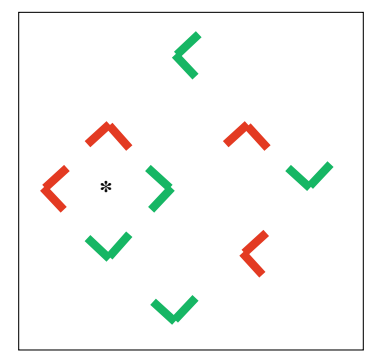

Outside Object (B)

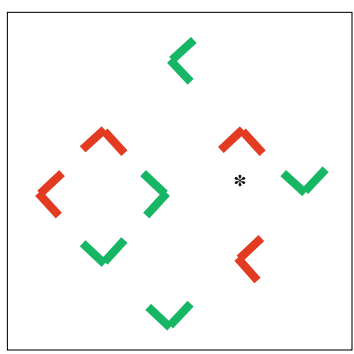

No Object (C)

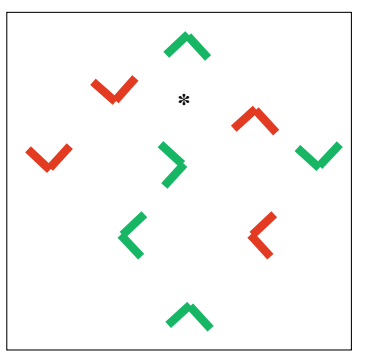

Fig. 2 Sample displays from Kimchi, Yeshurun, and CohenSavransky (2007). In the target display, a subset of the L-shaped elements formed a perceptual unit on some trials (see A and B) and no perceptual units on the other trials (see C). The target was specified in relation to the asterisk by an instruction word (e.g., above, below, left, or right) at the beginning of each trial. The task was to report the color of the target. The asterisk was inside the perceptual unit in the inside-object condition and outside the perceptual unit in the outsideobject condition. There was no perceptual unit in the no-object condition observed object-based attentional benefits in memory recognition tasks. Their participants had better recognition memory for letters whose onset coincided with, rather than mismatched, a sudden change that occurred to an object upon which the letters were shown. These results suggest the existence of an object-based attentional mechanism that underlies both scene perception and information retrieval. Attention to one part of an object appears not only to facilitate the speed of information manipulation pertaining to the attended object, but also to enhance the strength of encoding, resulting in better retrieval of the encoded information.

Object-based attention also influences the efficiency of visual search. In general, search efficiency increases with increasing similarity among the distractors and decreasing similarity between the target and the distractors. This perceptual grouping effect has been found with a variety of features, including color, shape, proximity, good continuation, connectedness, and even perceived surface in 3-D space (e.g., Banks \& Prinzmetal, 1976; Donnelly, Humphreys, \& Riddoch, 1991; Duncan \& Humphreys, 1989, 1992; Z. J. He \& Nakayama, 1995; Humphreys, Quinlan, \& Riddoch, 1989; Treisman, 1982; Wolfe \& Bennett, 1997). These results are presumably caused by the fact that, whereas the homogeneity of distractors promotes perceptual grouping, which in turn facilitates their rejection as a perceptual unit, the homogeneity between the target and distractors impairs segmentation, making it harder to distinguish the target from the distractors (Duncan \& Humphreys, 1989, 1992). Thus, a line segment was easy to detect when it appeared in isolation but was difficult to detect when it was embedded in a configuration (e.g., Rensink \& Enns, 1995). Similarly, visual statistical learning-that is, acquiring information about the frequency of stimulus pairing over successive trials - was easier when an attended stimulus was connected with the other (unattended) member of the pair than when the two stimuli were separated (e.g., Baker, Olson, \& Behrmann, 2004). Searching for two features was also more efficient when the target features belonged to a single object or perceptual group rather than to two different objects or perceptual groups (e.g., Goldsmith, 1998; Kahneman \& Henik, 1981; Wolfe \& Bennett, 1997). Finally, all else being equal, when a target and a probe differed in orientation, search was more efficient when the target was shown in its canonical orientation rather than in other orientations (e.g., Newell, Brown, \& Findlay, 2004). These results indicate that objectbased attention contributes to both scene perception and information retrieval in long-term memory.

Interestingly, object-based attention has also been found to influence some phenomena that are typically associated with low-level visual processing. Spivey and Spirn (2000) found that observers who viewed two colored gratings that overlapped in space but differed in orientation could selectively adapt to one of the gratings via attention, resulting in a tilt aftereffect in the direction opposite to the attended grating. Using a different paradigm, Mitchell, Stoner, and Reynolds (2004) demonstrated the effect of attention on dominance in binocular rivalry. They showed observers two patterns of dots that rotated in opposite directions. The patterns were projected to both eyes. After attention was cued to one pattern, the image of the cued pattern was removed from one eye while the image of the uncued pattern was removed from the other eye. Since the two eyes were now viewing different images, binocular rivalry occurred. Interestingly, although the dominant pattern shifted between the two eyes, as one would expect during binocular rivalry, it was more likely to be the cued pattern, rather than the uncued pattern. In subsequent experiments, Chong and Blake (2006) showed that in order to counteract the attentional effect of a cued grating on initial dominance in binocularly rivalry, the contrast of the grating had to be reduced by an amount in the neighborhood of 0.3 log-units. Taken together, these findings are consistent with the notion that attention can enhance the early representation of the selected item or its region (Desimone \& Duncan, 1995), a topic that I will discuss in more detail later. 
Although the majority of the literature on object-based attention demonstrates object-based facilitation, objectbased inhibition has also been explored. In a typical experiment that uses the inhibition of return (IOR) paradigm (Posner \& Cohen, 1984), a peripheral location is cued, followed by a central fixation and then a target at either the cued location or a new location. Target detection is facilitated at the cued location when the cue-to-target stimulus onset asynchrony is short (e.g., within $300 \mathrm{msec}$ ). However, when it is long (e.g., beyond $300 \mathrm{msec}$ ), responses to the target are slower at the cued location relative to an uncued location, demonstrating locationbased IOR. It has been proposed that the function of IOR is to prevent repeated sampling of locations that have already been searched (Klein, 1988).

Using dynamic displays with moving objects, a number of studies found object-based IOR (e.g., Chou \& Yeh, 2008; Gibson \& Egeth, 1994; Jordan \& Tipper, 1998, 1999; List \& Robertson, 2007; Tipper, Driver, \& Weaver, 1991; Tipper, Weaver, Jerreat, \& Burak, 1994). Tipper et al. (1991) cued attention to a moving object and found that IOR moved with the object to a new location, rather than remaining at the original environmental location. Gibson and Egeth (1994) showed their participants a computer-generated brick that rotated in 3-D and found both location- and object-based IOR. Relative to a control condition in which a cue and a subsequent target appeared at different locations on two different surfaces of the rotating brick, their participants were slower when the cue and target were on different surfaces but at the same environmental location (showing location-based IOR) and when the cue and target appeared on the same surface but at different environmental locations (showing object-based IOR). Similar results were reported in experiments using static displays (e.g., Chou \& Yeh, 2008; Jordan \& Tipper, 1999; List \& Robertson, 2007).

In addition to object-based IOR, object-based inhibition has been demonstrated in the negative priming paradigm. Negative priming refers to the longer RTs to a target on a probe trial (trial $n+1)$ when that target was a distractor rather than a neutral stimulus on a prime trial (trial $n$ ) (Tipper, 1985). In Tipper, Brehaut, and Driver (1990), participants saw stimulus displays that induced the perception of a target and distractor moving through occluding columns (i.e., the movement itself was never in view), with the target emerging a moment later at either the projected location of the distractor or a different location. Negative priming was found when the target on the probe trial emerged at the projected location of the distractor, even though this location was not the environmental location where the distractor was last seen. In other words, inhibition of the distractor did not simply stay at its original location. Instead, it moved with the inhibited object to its new location, despite the fact that the actual movement of the distractor was never seen.
Interestingly, negative priming can be eliminated and even become positive priming when the target and distractor are perceptually grouped in the prime display (e.g., Fuentes, Humphreys, Agis, Carmona, \& Catena, 1998). Taken together, these results are consistent with the notion of objectbased inhibition, suggesting that both facilitation and inhibition can spread across an object's surface and move with an attended object to its new location.

Object-based attention is not restricted to neurologically intact people. Patients with brain damage have also shown evidence of using an object-based reference frame in visual processing. Driver and Halligan (1991) showed pairs of vertically aligned nonsense shapes to their patient, P.P., who suffered from severe left neglect due to damage in her right temporo-parietal region. The task was to determine whether the pair of shapes, which were centrally presented, were the same or different. Since neglect is primarily a space-based attentional deficit (Bisiach \& Luzzatti, 1978), it was not surprising that P.P. performed the task poorly when the shapes differed on the left. Interestingly, when the shapes were tilted $45^{\circ}$ to the right, she continued to show poor performance when the shapes differed on their left side even though the differences were now in her intact right side of space. Similar results were reported by a number of other researchers (e.g., Behrmann \& Moscovitch, 1994; Caramazza \& Hillis, 1990; Driver, Baylis, \& Rafal, 1992; Marshall \& Halligan, 1994; Young, Hellawell, \& Welch, 1992). In all these studies, patients with neglect in their left visual field were less impaired in performance when the critical information was on the right side of the objects, even when the right side of the objects was in their impaired left side of space (cf. Farah, Brunn, Wong, Wallace, \& Carpenter, 1990).

A similar pattern of performance can be found in patients with visual extinction, which is a less severe form of neglect confined to a contralesional stimulus when it is presented concurrently with an ipsilesional stimulus. It has been shown that patients with visual extinction can reduce their deficits when the contralesional stimulus is perceptually grouped with the ipsilesional stimulus (e.g., Mattingley, Davis, \& Driver, 1997; Ward, Goodrich, \& Driver, 1994). Grouping also improves the perceptual impairments of patients with Balint's syndrome, who typically see only one object at a time. Humphreys and Riddoch (1993) tested two Balint's patients, whose performance in perceiving multiple objects improved remarkably when differentcolored objects were connected by black lines. Other object properties also appear to influence the extent of deficits in brain-damaged patients. Humphreys and colleagues (Humphreys \& Riddoch, 2003; Humphreys, Romani, Olson, Riddoch, \& Duncan, 1994) found that their patients, who had parietal lobe damage, showed differential degrees of extinction as a function of object type. For example, when 
pairs of stimuli were shown simultaneously, extinction was more likely to occur with an open geometric shape rather than a closed geometric shape. Remarkably, these patients were often unable to locate the stimulus they had just successfully identified. As Humphreys and his colleagues noted (Humphreys \& Riddoch, 2003; Humphreys et al., 1994), these results suggest that when spatial selection was impaired, the grouping strength between the components of an object could influence the probability of an object being selected, with the object-based selection system favoring the object having the stronger grouping. Moreover, the finding that damage in the parietal lobe could impair the explicit representation of space while leaving the implicit coding of location intact suggests that multiple forms of spatial representation exist in the brain, and not all of them can be accessed explicitly.

\section{Factors that influence object-based selection}

Most studies modeled after Egly, Driver, and Rafal (1994) have used exogenous (peripheral) instead of endogenous (central) cues to direct attention to a specific location in an object. In general, object effects are more readily demonstrated with exogenous than with endogenous cues. Macquistan (1997) used Egly, Driver, and Rafal's tworectangular paradigm but showed one group of participants an exogenous cue and another group an endogenous cue before the onset of the target. Object effects were found with exogenous but not endogenous cues. Similar results were reported by Dagenbach and colleagues (Arrington, Dagenbach, McCartan, \& Carr, 2000, November; Dagenbach, Goolsby, Neely, \& Dudziak, 1997; Neely \& Dagenbach, 1996). These findings led some researchers to question whether endogenous control of object-based attention was possible (e.g., Lauwereyns, 1998; Macquistan, 1997).

However, later research has shown that it is not the type of cue but, rather, the different extent of attentional focus elicited by a cue that determines the presence or absence of an object effect. Goldsmith and Yeari (2003) noted that because exogenous cues are typically situated peripherally and endogenous cues centrally, participants are more likely to adopt a broad attentional focus with the former and a narrow attentional focus with the latter (see Fig. 3). Since a narrow (central) attentional focus presumably weakens the object representation when the objects are relatively large or peripherally located, object effects are more elusive with endogenous than with exogenous cues. Goldsmith and Yeari went on to show that when participants were induced to adopt a broad attentional focus through either task demand or explicit instruction, object effects could be found with endogenous cues. Consistent with this extent-of-attentionalfocus account, object effects were found in several other studies that used endogenous cues (e.g., Abrams \& Law, 2000; Chen \& Cave, 2008; Law \& Abrams, 2002). In addition, object effects were more reliable when the task encouraged a wide rather than a narrow deployment of attention (e.g., Lavie \& Driver, 1996; Shomstein \& Yantis, 2002; but see Lamy, 2000, for failure to replicate the finding of Lavie \& Driver, 1996) and when shifts of attention were required (e.g., Brown \& Denney, 2007; Lamy \& Egeth, 2002; Shomstein \& Yantis, 2002).

For object-based attention to be deployed, a robust object-based representation must be established. Thus, variables that affect the quality of object-based representations also influence the degree to which object-based attention is utilized. One such variable is stimulus presentation duration. Object effects are less reliably elicited with short, relative to long, display durations (e.g., Avrahami, 1999; Chen \& Cave, 2008; Law \& Abrams, 2002). In Chen and Cave (2008), participants demonstrated object effects when they had $1,005 \mathrm{~ms}$ to view a stimulus display before the appearance of a precue. No object effects were found when the viewing time was decreased to $120 \mathrm{~ms}$. Similar effects of display duration were reported by Avrahami, who manipulated the cue-to-target stimulus onset asynchrony (420 vs. $210 \mathrm{~ms}$ ), and by Law and Abrams (2002), who varied the target display duration across experiments (186 vs. $129 \mathrm{~ms}$ ). In both cases, object effects were more evident with the long, rather than the short, display duration. However, object effects have also been found with display durations as brief as 50 ms (e.g., Duncan, 1984). Given the diverse durations that have elicited object effects, it seems that the exact stimulus presentation duration may not really matter. Instead, what matters is the quality of object-based representation that a specific duration allows the participants to establish, which can be influenced by a variety of factors, including task demand, stimulus characteristics, and response mode. Consistent with this idea is the finding by Ariga, Yokosawa, and Ogawa (2007), who used a modified version of Egly, Driver, and Rafal's (1994) two-rectangle

\section{Exogenous Cue}

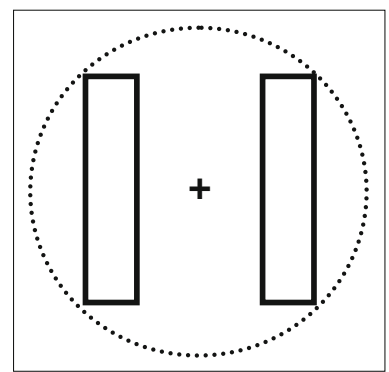

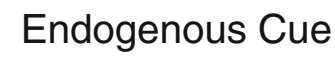

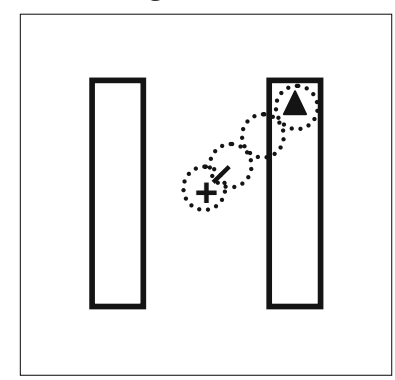

Fig. 3 The extent of attentional focus, which is shown within the dotted circle, on a typical trial when an exogenous cue is used and when an endogenous cue is used (adapted from Goldsmith \& Yeari, 2003) 
paradigm and found no evidence of object-based attention when their participants were not consciously aware of the presented objects (but see Mitroff \& Scholl, 2005, for evidence of forming and updating object representations when changes were made to unseen stimuli during motioninduced blindness).

Another factor that contributes to the quality of objectbased representation is the "goodness" of an object. All else being equal, a "good" object is one that has surface uniformity and closed boundaries. Thus, object effects are more reliable when objects show uniform connectedness-for example, when objects have the same color and luminance, as compared with various colors or luminance (e.g., Hecht \& Vecera, 2007; Kramer \& Watson, 1996; Matsukura \& Vecera, 2006; Watson \& Kramer, 1999), when they have closed rather than open boundaries (e.g., Marino \& Scholl, 2005), and when targets appear on the same straight line within an object, rather than on different segments of an object separated by angles (e.g., Crundall, Cole, \& Galpin, 2007).

Object effects are also more robust when the perceptual load is low rather than high (e.g., Ho \& Atchley, 2009), when the observers are young rather than old (e.g., McCrae \& Abrams, 2001), when the motor responses required are grasping rather than pointing (e.g., Fischer \& Hoellen, 2004; Linnell, Humphreys, McIntyre, Laitinen, \& Wing, 2005; but see Bekkering \& Pratt, 2004, for object-based effect with pointing), and when the left rather than the right hemisphere receives object-related information (e.g., Egly, Driver, \& Rafal, 1994; Egly, Rafal, Driver, \& Starreveld, 1994).

As with display duration, factors that promote the "goodness" of an object are conducive to the deployment of object-based attention, but they are not a necessary condition. Object effects have been obtained in objects without closed boundaries (e.g., Avrahami, 1999, Crundall et al., 2007; Kramer \& Jacobson, 1991) or uniform surfaces (e.g., Hecht \& Vecera, 2007). Moreover, it has been found in objects created through illusory contours (e.g., Moore et al., 1998) and amodal completion (e.g., Behrmann et al., 1998; Matsukura \& Vecera, 2006; Moore et al., 1998; Pratt \& Sekuler, 2001; but see also Saiki, 2000, for an alternative interpretation of Behrmann et al., 1998). These results suggest that the formation of an object representation, regardless of the manner through which such a representation is established, is a critical factor in the deployment of objectbased attention.

Support for the statement above is perhaps best found in experiments showing that object-based attention can appear or disappear via the manipulation of an observer's subjective organization of a stimulus configuration. In several experiments, Chen (1998) showed her observers displays that resembled two colored $V_{\mathrm{S}}$ that were partly superimposed at the base (see Fig. 4). When the stimulus configuration was described as two $V \mathrm{~s}$, observers were faster at switching attention between the two arms of the same $V$, as compared with two arms of different $V$ s, demonstrating object-based attention. However, when the same configuration was described as an $X$ made of two different colors, the effect was eliminated. Similar findings were reported by $\mathrm{Li}$ and Logan (2008) and Albrecht, List, and Robertson (2008). In $\mathrm{Li}$ and Logan, skilled Chinese readers showed object effects when they switched attention between Chinese characters that were part of a word, relative to parts of two words. In Albrecht et al., object effects were found when regions were perceived as foreground objects, but not when they were perceived as part of the background. Since objects were defined in these studies by top-down processing, such as subjective organization or the semantic relationship between different stimuli while the physical features of the stimuli were held constant, these results provided unambiguous evidence supporting the notion that the most critical factor in eliciting the deployment of object-based attention is the establishment of a viable object representation.

\section{Mechanisms that give rise to object effects}

There are three main interpretations regarding the mechanisms that give rise to object effects: sensory enhancement, attentional prioritization, and attentional shifting. The sensory enhancement interpretation emphasizes the spread of attention that respects object boundaries and attributes object effects to the improved sensory representation of the selected object (e.g., Avrahami, 1999; Chen \& Cave, 2006, 2008; X. He, Fan, Zhou, \& Chen, 2004; Martínez, TederSälejärvi, \& Hillyard, 2007; Richard et al., 2008; Roelfsema \& Houtkamp, 2011; Roelfsema, Lamme, \& Spekreijse, 1998; Valdes-Sosa, Bobes, Rodriguez, \& Pinilla, 1998,

\section{Two Vs}

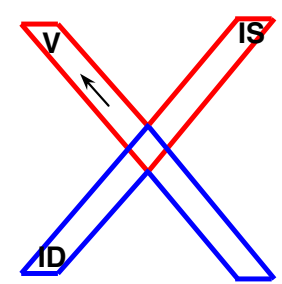

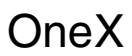

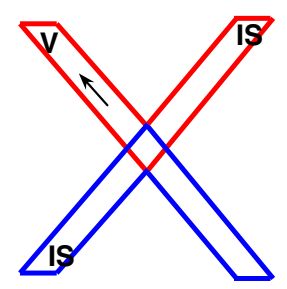

Fig. 4 Stimuli adapted from Chen (1998). The same stimulus configuration was described as two $V_{\mathrm{S}}$ superimposed at the base to some observers but as an $X$ made of two different colors to the other observers. When the configuration was perceived as two $V \mathrm{~s}$, an object effect was found. Switching attention within a $V$ was faster than switching attention between two $V$ s. However, when the configuration was perceived as an $X$, there was no significant difference in RT when the switch of attention was within the same color region or between two different color regions. The location of the target is represented here by $\mathrm{V}$ for valid trials, IS for invalid same-object trials, and ID for invalid different-object trials. The arrow indicates a precue 
Vecera \& Farah, 1994; Weber, Kramer, \& Miller, 1997). The attentional prioritization account (as originally presented) stresses the biasing of attentional scanning order in visual search, which, by default, starts from the locations within an already attended object (e.g., Shomstein \& Yantis, 2002, 2004). Finally, the attentional shifting account emphasizes the relatively higher cost of attentional shifts between objects, relative to within an object (e.g., Brown \& Denney, 2007; Lamy \& Egeth, 2002), and attributes this betweenobject cost to the additional disengagement operations when attention needs to be disengaged from an object to a location outside that object (Brown \& Denney, 2007).

When the object-based attentional effect was first reported, it was explained in terms of selecting either the internal representation of the region of space occupied by an attended object (e.g., Kim \& Cave, 1995, 2001; Kramer et al., 1997) or the internal representation of a locationindependent object (e.g., Vecera \& Farah, 1994). Vecera and Farah referred to these two types of selection as grouped-array and spatially invariant representations, respectively. In both cases, it is assumed that the spread of attention respects object boundaries and that attention improves the quality of the perceptual representation of the selected item. The attentional enhancement is likely to be the result of biased competition (Desimone \& Duncan, 1995) among neural representations of multiple objects, causing the representation of the attended object to become more effective in its competition with the representations of the other, unattended objects. The selection of the attended object, in turn, leads to faster and/or more accurate processing of the features or items within the object, as compared with those in the nonselected objects.

Early evidence supporting the sensory enhancement account can be found in experiments using single-cell recordings (e.g., Roelfsema et al., 1998; Wannig, Rodríguex, \& Freiwald, 2007). Roelfsema et al. (1998) measured the responses of neurons in V1 while monkeys were performing a curve-tracing task (see Fig. 5). The monkeys were shown two curves on each trial: a target curve, which was directly connected to a fixation point, and a distractor curve, which was not connected with the fixation. On each trial, the monkeys made a saccade to a small circle at the end of the target curve. The results showed that neurons in V1 responded more vigorously when their receptive fields were on the target curve, as compared with the distractor curve. Moreover, this enhancement occurred in neurons whose receptive fields were on different segments of the target curve, relative to different segments of the distractor curve, regardless of whether the two curves were spatially separated or crossed each other. Recent experiments further revealed that the onset of the enhancement of the neurons whose receptive fields were on the target curve differed as a function of the spatial distance between their receptive fields and the fixation, with the onset delayed for those neurons whose receptive fields were farther away from the fixation (Roelfesema \& Houtkamp, 2011; cf. Roelfsema et al., 1998). These results support the notion that attention spreads within an object. They are also consistent with the performance of human observers in mental curve tracing tasks (e.g., Houtkamp, Spekreijse, \& Hoelfsema, 2003), showing that the spread of attention is a gradual process that takes time to complete.

In addition to neurons in V1, the target enhancement effect has also been reported with motion-sensitive neurons in the middle temporal area (MT) of monkeys. Wannig et al. (2007) cued monkeys to attend to one of two transparent random-dot surfaces and found that the motion of the attended surface activated the neurons in MT more strongly than the motion of the unattended surface, even though the two surfaces occupied the same spatial region. These results provide a direct link between attention to an object or surface and increased neural activation of the representations of the selected object or surface in early sensory areas.

Changes in neuronal responses have also been observed in experiments using event-related brain potentials (ERPs). Valdes-Sosa et al. (1998) showed their observers stimulus displays consisting of two sets of superimposed dots that differed either in both color and the direction of motion, thus

(a)

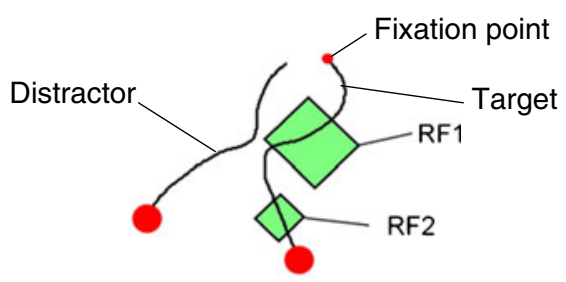

(b)
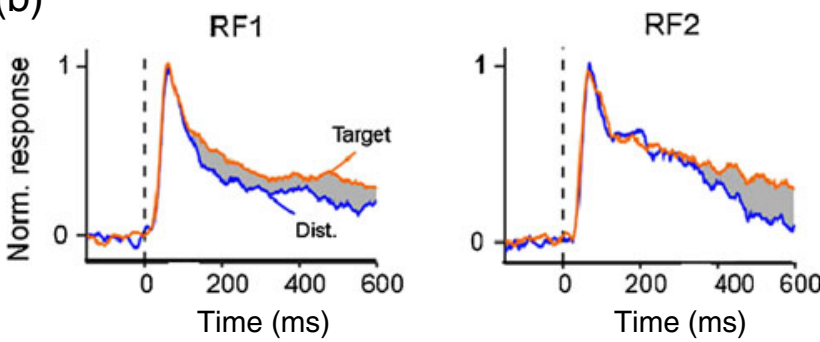

Fig. 5 Sample stimuli and data adapted from Roelfsema and Houtkamp (2011). a Monkeys were trained to perform a curve-tracing task by making a saccade to the target upon a signal. The target was the circle connected to the fixation point. RF1 and RF2 represent the recording sites for the neurons in $\mathrm{V} 1$ whose receptive fields were located on different segments of the target or distractor curve. b Responses of neurons whose receptive fields were in RF1 and RF2. Note that the neurons responded more vigorously when their receptive fields were on the target curve, as compared with the distractor curve. Furthermore, the onset of the enhancement of the neurons whose receptive fields were farther away from the fixation was delayed, relative to that of the neurons whose receptive fields were closer to the fixation 
creating the perception of two transparent surfaces in rigid rotation (the two-object condition), or in color but not in the direction of motion, thus creating the perception of one object either at rest or rotating in the same direction (the one-object condition). The participants judged the direction of motion of a subset of the dots (defined by color) that simultaneously underwent brief linear displacements (i.e., nonrotational motion). Their motion-onset ERPs were recorded while the target dots changed locations. Motiononset posterior $\mathrm{P} 1$ and $\mathrm{N} 1$ components were found to be associated with both the attended and the unattended sets of dots in the one-object condition, but with only the attended set of dots in the two-object condition. In the latter case, a strong suppression of P1 and N1 was observed with the unattended object. These findings are consistent with the notion that object effects are the result of changes in the neural representations of the selected object. They also suggest that both the enhancement of the attended object and the suppression of the unattended object may play a role in the observed object effects. Results in support of the sensory enhancement account can also be found in a number of other ERP experiments, including X. He et al. (2004, 2008), Martínez et al. (2007; Martínez et al., 2006), and Weber et al. (1997). Despite the differences in their methodology (e.g., using exogenous or endogenous cues or a postdisplay probe to measure the distribution of spatial attention), a common finding is that object-based attention is associated with an enhanced N1 component over the occipito-temporal areas (but see Weber et al., 1997, for a larger N1 amplitude in the different-object condition than in the same-object condition).

Experiments using functional magnetic resonance imaging (fMRI) have provided converging evidence in support of the sensory enhancement account (e.g., Arrington, Carr, Mayer, \& Rao, 2000; Martínez, et al., 2006; Müller \& Kleinschmidt, 2003; O’Craven, Downing, \& Kanwisher, 1999). O'Craven et al. showed their participants semitransparent images of a face and a house that were spatially superimposed. On each trial, either the face or the house would move while the other remained stationery. The participants attended to the face, the house, or the motion in different conditions. The results showed that attention to one attribute (e.g., the face) led to an enhanced blood oxygenation level dependent (BOLD) signal change not only in the brain area associated with the processing of that attribute (i.e., the fusiform face area, which is involved in the processing of faces), but also in the brain area associated with the processing of the task-irrelevant attribute (i.e., the MT/ MS area for motion) that belonged to the attended object rather than the unattended object. The finding that neural activation pertaining to a task-irrelevant attribute differs as a function of whether that attribute was part of an attended or an unattended object supports the notion that attention leads to enhanced neural representations of all the attributes that belong to the selected object regardless of task relevancy. Arrington, Carr, et al. (2000) further showed that attending to a region of space bounded by an object evoked stronger brain activity, as compared with attending to an empty space not bounded by any object. This result indicates that objectbased spatial selection requires additional mental resources over and beyond location-based spatial selection. It should be noted, however, that the results above do not entail that the degree of enhanced activation is equivalent in all the regions of the selected object. In fact, Müller and Kleinschmidt (2003), whose study I will describe in more detail in the next section, found a larger increase in BOLD signal activation at the cued location than at uncued locations in early visual areas (V1-V4). A similar finding was reported by Martínez et al. (2006) in an ERP experiment where they observed a smaller N1 amplitude associated with objectbased attention than with space-based attention.

Shomstein and Yantis (2002) noted that many experiments that demonstrated object effects required observers to shift attention from one location to another within a trial (e.g., Chen, 1998; Egly, Driver, \& Rafal, 1994; Moore et al., 1998). If the default scanning in visual search is to start from locations within an already attended object, this would result in the uncued locations of the attended object being searched before any locations of the unattended object, and this, in turn, would lead to reduced RTs and/or increased accuracy when the target appears in the same object, relative to a different object. In other words, object effects can be the result of attentional prioritization in visual search, rather than the result of attentional spread that respects object boundaries.

To test this hypothesis, Shomstein and Yantis (2002) manipulated the spatial uncertainty of a target across experiments. The rationale was the following: If the critical factor in triggering object-based attention was scanning order in visual search, knowing the location of the target in advance should eliminate the need for search, resulting in no object effects. The participants saw stimulus displays that resembled a cross: a large rectangle in one orientation (either horizontal or vertical) flanked by a pair of small rectangles in an orthogonal orientation (see Fig. 6). On each trial, a target and two distractor letters, which indicated either the same response or different responses, would appear within the boundaries of the configuration. On some trials, all the letters were within the same rectangle. On the other trials, the target was on one rectangle, and the distractors were on different rectangles. In four experiments (Experiments 1-4), the target always appeared at the center, so there was no need to shift attention to locate the target. Although flanker interference effects (B. A. Eriksen \& Eriksen, 1974) were found, i.e., RTs were shorter when the target and distractors indicated the same response relative to different responses, 


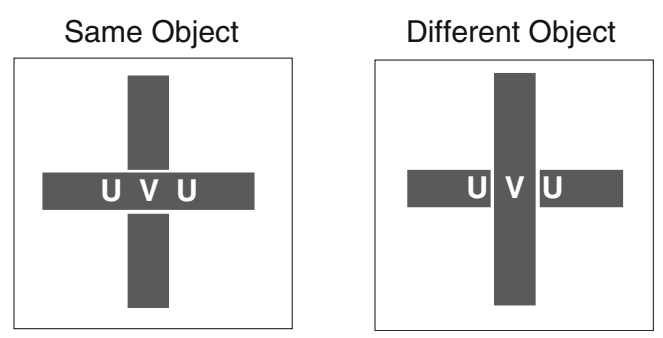

Fig. 6 Sample stimuli adapted from Experiments 1-4 of Shomstein and Yantis (2002). The target display consisted of a target letter and two distractor letters. The target was always the central letter, and the distractors indicated either the same response as the target or a different response from the target. The target and distractors were on the same object in the same-object condition and on different objects in the different-object condition. The magnitude of the distractor interference effects was comparable in the same- and different-object conditions, indicating no object effects

there was no evidence of an object effect. That is, the magnitude of the interference effects was comparable regardless of whether the target and distractors were on the same object or on different objects. In contrast, when the location of the target was made unpredictable in a subsequent experiment so that observers had to search for the target, an object effect was found, as indicated by larger flanker interference when the target and distractors were on the same object than when they were on different objects. In later studies, Shomstein and colleagues (Shomstein \& Yantis, 2004; Shomstein \& Behrmann, 2008) showed that even when the location of a target was unpredictable, object effects could be eliminated when the probability of a target's appearing on a different object was substantially higher (e.g., $47 \%$ ) than that of a target's appearing at a different location of the cued object (e.g., $7 \%$ ). These results were interpreted as evidence that the order of visual search is a critical factor in the manifestation of object effects, in line with the attentional prioritization account (Shomstein \& Behrmann, 2008; Shomstein \& Yantis, 2004).

A key prediction of the attentional prioritization account is that object-based attention would not be deployed when the location of a target is known in advance, since the positional certainty of the target would eliminate the need for search and would result in the target location being allocated the highest attentional priority. Although this prediction was confirmed in Shomstein and Yantis (2002), other studies have shown object effects when the location of the target was known in advance (e.g., Chen \& Cave, 2006, 2008; Harms \& Bundesen, 1983; Kim \& Cave, 2001; Kramer \& Jacobson, 1991; Richard et al., 2008). Chen and Cave (2006) used an experimental paradigm similar to that used in Shomstein and Yantis (2002, Experiments 1-4), where the target always appeared at the center of a crosslike configuration. While no object effect was found when participants saw the full cross-like configuration on every trial, it was observed when that configuration appeared on only some of the trials, with the rest of the trials consisting of displays that showed only one or two of the three rectangles. These results are inconsistent with the attentional prioritization account. Chen and Cave (2006) suggested that mixing the partial displays with the full displays prompted the participants to perceive the stimulus pattern as separate objects, rather than as a single configuration (e.g., a cross). Since subjective organization of a stimulus pattern is known to affect the deployment of object-based attention (e.g., Albrecht et al., 2008; Chen, 1998; Li \& Logan, 2008), these results suggest that the key factor in the lack of an object effect in Shomstein and Yantis (2002) may be the perceived structure of the stimulus configuration, rather than the lack of need for visual search.

Object effects with positional certainty have also been found in Harms and Bundesen (1983), Kim and Cave (2001), and Kramer and Jacobson (1991). These studies all showed that grouping influenced the allocation of attention despite the fact that the target appeared at a known location on every trial. In addition, the observers in Chen and Cave (2008) responded faster to letters located at the two ends of a single object, relative to two ends of different objects, even though in both cases the onset of the targets was preceded by an endogenous central cue of $100 \%$ validity. Richard et al. (2008) used a flanker interference paradigm with a centrally located target and found object effects when the target was a part of an object (i.e., belonged to the object), but not when it was a letter sitting on top of a rectangle. On the basis of their results, Richard et al. proposed that the key factor in obtaining object-based attention under the condition of positional certainty was the perception of the task-relevant feature as an integral part of an object shape, rather than as something perceptually segregated from the object shape. It should be pointed out, however, that this interpretation did not explain why object effects were observed in other studies where the task-relevant feature was clearly not an integral part of an object shape (e.g., Chen \& Cave, 2006, 2008). Regardless of what induced the object effects found in Richard et al., the finding of an object effect even when the location of the target was known in advance suggests that object effects are not just a by-product of the order in which different regions of a scene are visited during visual search.

To date, the strongest physiological evidence supporting the within-group spread of attention has come from several recent studies by Roelfsema and colleagues (e.g., Roelfsema \& Houtkamp, 2011; Wannig, Stanisor, \& Roelfsema, 2011). In one experiment by Wannig et al. (2011), monkeys were shown displays that consisted of two target bars and two distractor bars. The task was to fixate on a fixation point, to wait for a dot to appear at one of the target bars, and upon the offset of the dot, to make a saccade to the indicated target bar. The researchers simultaneously recorded the 
responses of V1 neurons from two sites: site 1 for those neurons whose receptive field was on one of the target bars, and site 2 for those neurons whose receptive field was on one of the distractor bars. The results show that the appearance of the dot in the receptive field of site 1 triggered not only an increase in activity in those neurons whose receptive field was in site 1, but also an increase in those neurons whose receptive field was in site 2. Furthermore, the activity of the neurons was stronger when site 2 was on a distractor bar collinear to the target bar (i.e., in the same perceptual group), rather than when the two bars were not aligned collinearly (i.e., in different perceptual groups). Similar results were observed for perceptual groupings based on color or common fate. Since site 2 was on a distractor bar, these results provided direct evidence that attention could spread to task-irrelevant stimuli outside the focus of attention and that the attentional enhancement was greater when these stimuli were bound to the attended stimulus through one or more Gestalt grouping principles.

More recently, Drummond and Shomstein (2010) suggested that in addition to search order, attentional prioritization can also be the result of a parallel search process where information at different locations of a configuration is extracted at different rates according to attentional priority and that attentional prioritization can affect the quality of the sensory representation of an attended object. In this revised model, there is little difference between the attentional prioritization account and the sensory enhancement account.

As was mentioned earlier, object effects have also been explained in terms of the relative cost of shifting attention within an object versus between objects (Brown \& Denney, 2007; Lamy \& Egeth, 2002). Lamy and Egeth used a variant of Egly, Driver, and Rafal's (1994) two-rectangle paradigm and asked their participants to perform tasks that either required or did not require shifts of attention. Object effects were found in the former but not in the latter. For example, the participants demonstrated an object effect when the task was to detect the presence of a target, and its onset was preceded by a precue indicating the most likely location of the target. In contrast, there was no evidence of an object effect when the task was to judge the size of two simultaneously presented targets whose onsets were not preceded by a precue. Lamy and Egeth interpreted these results in the context of required attentional shifts within a trial (cf. Drummond \& Shomstein, 2010). Whereas the precue in the detection task encouraged the participants to switch attention from the cued location to the target location, the simultaneous onset of a pair of targets with no precue in the size judgment task induced the participants to adopt a diffuse attentional window without the need to switch attention. Since shifting attention between objects is more difficult and, therefore, has a higher cost than shifting attention within an object, object effects are typically found in cuing paradigms where the location of the target is uncertain and attentional shifts are required within a trial.

Building on Lamy and Egeth's (2002) results, Brown and Denney (2007) investigated the role of the individual component of attention that contributed to the cost in the between-object shift of attention. According to Posner and his colleagues (e.g., Posner \& Cohen, 1984; Posner \& Peterson, 1990), the process of shifting attention consists of three separate operations: disengagement (i.e., the release of attention from a current location), movement (i.e., the switching of attention from one location to another), and engagement (i.e., the focusing of attention to a new location). To investigate the disengagement and engagement operations, Brown and Denney designed a series of tasks that required participants to switch attention in a variety of ways (see Fig. 7). In addition to performing tasks in a tworectangle display that involved shifting attention within an object or between two objects (the two-invalid-within condition and the two-invalid-between condition, respectively), the participants also saw one-rectangle displays that required them to shift attention between two locations inside the same rectangle (the one-invalid-within condition), two locations outside the rectangle (the one-location-to-location condition), from a location inside the rectangle to a location outside (the one-object-to-location condition), and from a location outside the rectangle to a location inside (the onelocation-to-object condition), among others. Two main results were found. First, disengaging attention from an object was associated with an additional cost over and above that of disengaging attention from a location or shifting attention within an object. This was indicated by the longer RTs in the object-to-location condition than in the locationto-object condition, location-to-location condition, and invalid-within-object condition. Second, engaging attention to an object after attentional movement did not necessarily incur an extra cost, relative to engaging attention to a location. This was evidenced by comparable RTs between the object-to-location condition and the two-object-invalid-between condition. On the basis of these results, Brown and Denney proposed that shifting attention from a location and from an object may involve different or separate processes (see also Arrington, Carr, et al., 2000) and that object effects reflect primarily the cost of disengagement operations associated with the object-based attention. It should be noted, however, that other researchers have shown object effects under situations where attentional shifts are not required (e.g., Chen \& Cave, 2006; Duncan, 1984; Harms \& Bundesen, 1983; Kim \& Cave, 2001; Kramer \& Jacobson, 1991; Richard et al., 2008), suggesting that the cost in between-object attentional shifts may be one of several factors that contribute to object effects.

Taken together, the available evidence suggests that there is substantial flexibility in how attention is distributed within an 
object and how fully a stimulus configuration is segregated into objects. Many factors, including those reviewed in the previous section (e.g., attentional focus, "goodness" of an object, etc.) and the probability of the target's appearing within a cued versus an uncued object, all influence the deployment of object-based attention. Attention spreads within an object, yet the spreading of attention is not necessarily automatic. Furthermore, although object segregation may often be triggered spontaneously, it is not an automatic process. Object segregation and/or object-based allocation of attention as a result of object segregation can all be subject to strategic control (Yeari \& Goldsmith, 2010).

\section{The role of space in object-based selection}

Although many studies have shown that location plays a special role in selective attention (e.g., Cave \& Pashler, 1995; Chen, 2009; Kim \& Cave, 1995; Tsal \& Lavie, 1993; for reviews, see also Cave, in press; Lamy \& Tsal, 2001), the role of space in object-based selection is not straightforward. Whereas some studies have reported results consistent with object-based attention selecting a location-independent representation, where attention selects the features of an attended object, such as its shape, color, orientation, and texture, without selecting its spatial location (e.g., Awh, Dhaliwal, Christensen, \& Matsukura, 2001; Matsukura \& Vecera, 2011; O’Craven et al., 1999; Vecera \& Farah, 1994), other studies have found that object-based attention selects from a location-mediated representation, where attention selects the regions of space occupied by the attended object (e.g., Arrington, Carr, et al., 2000; Kim \& Cave, 1995; Kramer et al., 1997; Martínez et al., 2007; Martínez et al., 2006; Müller \& Kleinschmidt, 2003; Valdes-Sosa et al., 1998; Vecera \& Farah, 1994; Weber et al., 1997). As was mentioned earlier, Vecera and Farah (see also Vecera, 1994) referred to these two types of selection as spatially invariant and grouped-array selection, respectively.

The first study to distinguish between these two types of selection was conducted by Vecera and Farah (1994), who used a variant of Duncan's (1984) bar-on-box paradigm. Participants saw displays that consisted of a bar and a box that were either superimposed at fixation (the superimposed condition) or positioned in separate spatial locations on the left or right of fixation (the separated condition). The task was to report two features that belonged to the same object or to different objects. Vecera and Farah reasoned that selection from a location-invariant representation would result in an object effect of comparable magnitude from both the superimposed and separated conditions. In contrast, selection from a location-mediated representation would lead to a larger object effect in the separated condition than in the superimposed condition. Implicit in this reasoning was the assumption that the cost of switching attention between objects would increase with their spatial separation (see Kramer et al., 1997, for arguments against this assumption; but see also Vecera, 1997, for counterarguments). The results showed that the object effects were comparable in the superimposed and separated conditions. Moreover, in a subsequent experiment where the task was stimulus detection instead of feature identification, a larger object effect was observed in the separated condition than in the superimposed condition. On the basis of these results, Vecera and Farah concluded that object-based attention could select from both location-independent and location-mediated representations and that the level of selection in a specific task depended on the nature of the representations required by the task.

Kramer et al. (1997) later challenged these conclusions. In two experiments, they measured observers' object-based deployment of attention and their distribution of spatial attention within the same paradigm. Observers saw a bar and a box that were either superimposed or separated in space. To hold visual acuity constant across the two conditions, the bar and the box in the superimposed condition were displayed on the left or right side of fixation, with a filler on the other side. In addition to reporting object features that were part of the same or different objects, the observers, on a small number of trials, were also required to detect the presence of a small probe when it appeared immediately after the offset of the object display. These postdisplay probe trials were included to measure observers' distribution of spatial attention (Kim \& Cave, 1995). A larger object effect was found in the feature identification task in the separated condition, as compared with the superimposed condition. Moreover, RT to the probe was shorter when it appeared at the location of the object that possessed both of the target features, rather than at the location of the object that possessed neither of the target features. These results suggest that the location of the attended object was selected even when the task was feature identification. Importantly, a similar probe RT result was observed in a subsequent experiment, where Kramer et al. (1997) placed the objects in the superimposed condition at fovea, as in Vecera and Farah's (1994) original study, and replicated the latter's results of comparable object effects in the superimposed and separated object conditions. Taken together, these results support the notion that object-based attention is accompanied by the selection of the internal representation of an object's location.

Several other studies have reported findings consistent with a location-mediated selection of object-based attention. Using a paradigm that involved moving objects, Lamy and Tsal (2000) found attentional effects both at the old location of a precue (i.e., the cued location of an object before it started to move) and at the new location that followed the moving object. Similarly, O'Grady and Müller (2000) reported increased target detectability at all the locations 
Two-InvalidWithin (A)

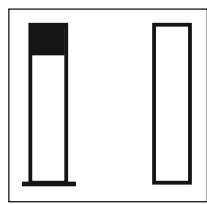

One-Invalid Within (C)

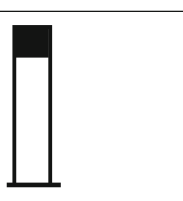

One-Object-toLocation (D)

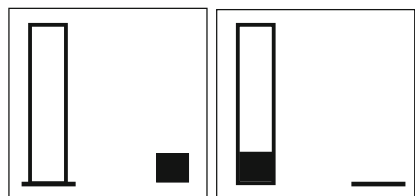

Fig. 7 Sample stimuli adapted from Brown and Denney (2007). a and b Conditions in two-object displays. $\mathbf{c}-\mathbf{f}$ Conditions in one-object displays

along the contour of a cued object, relative to an uncued object. Müller and Kleinschmidt (2003) measured their participants' BOLD signals during a gap discrimination task in an fMRI study. The participants saw displays that consisted of wrench-like objects. A central cue, which was several seconds long, indicated the most likely location of the target. As in a typical experiment on object-based attention, the target could appear at the cued location (the valid condition) or at an uncued location either on the cued object (the invalid same-object condition) or on the other object (the invalid different-object condition). Both space and object effects were found in RTs. Moreover, participants showed an increase in BOLD signal activation in response to the cue in early visual cortical areas (V1-V4) at the retinotopic representations of not only the cued location relative to the uncued locations, but also the uncued location of the same object relative to that of a different object. These results were in line with the findings of Roelfsema and colleagues (Roelfsema et al., 1998; Wannig et al., 2011), who showed object-based modulations of neuronal responses in V1. The fact that object-based attention modulated neural activation in the early visual areas provides evidence that attending to an object entails the selection of that object's location.

A similar conclusion was reached by Weber et al. (1997) in an ERP study. Observers saw two partially overlapping objects on either the left or right side of fixation. The task was to judge whether a prespecified color/shape conjunction was present in the display. The task-relevant features, if present, were on either a single object (the same-object condition) or two different objects (the different-object condition). On some trials, a task-irrelevant small probe would appear after the offset of the target display. These probe trials did not require overt responses. However, the participants' ERPs in response to the onset of the probe were measured. The results most relevant here were the findings from the probe trials.
When the probe appeared at the location previously occupied by objects that contained the target features, a larger P1 was found in the same-object than in the different-object condition. Since P1 is known to indicate the distribution of spatial attention (e.g., Hillyard et al., 1996; Luck, Heinze, Mangun, \& Hillyard, 1990), this result, together with the results from other ERP studies (e.g., Martínez et al., 2007; Martínez et al., 2006) and fMRI and single-cell recording studies (e.g., Müller \& Kleinschmidt, 2003; Roelfsema et al., 1998), provides physiological evidence supporting the location-mediated selection of object-based attention.

Matsukura and Vecera (2011) recently proposed that a spatially invariant representation could occur under conditions when objects were clearly segregated. They showed participants displays that consisted of a bar superimposed on a box. Object effects were found when attention could be directed to a specific object or objects in advance (e.g., when participants knew one or both of the to-be-reported features before the onset of the object display), but not when the knowledge of the to-be-reported features was withheld until after the offset of the object display. However, when the bar and the box were shown in different colors at separate spatial locations, object effects were observed in the absence of advance knowledge of the to-be-reported features when the objects were in view. Furthermore, the magnitude of the object effect was not influenced by the extent of spatial separation between the objects $\left(2.48^{\circ}\right.$ vs. $\left.5.24^{\circ}\right)$. On the basis of these results, Matsukura and Vecera concluded that object-based attention could select from space-invariant representations so long as the objects in question could be easily individuated. However, caution should be taken in interpreting these results, for there is evidence that spatial attention does not necessarily shift in an analog fashion (e.g., C. W. Eriksen \& Murphy, 1987; Yantis, 1988). Perhaps the role of space in object-based selection is best illustrated in a recent study by Hollingworth, Maxcey-Richard, and Vecera (2012), who found interaction between space- and object-based attention within the same experimental paradigm. Consistent with the notion that there are linkages between lowerlevel spatial representations and higher-level spatially invariant representations at multiple levels of selection (Di Lollo, Enns, \& Rensink, 2000; Hochstein \& Ahissar, 2002; Roelfsema \& Houtkamp, 2011; van der Velde \& de Kamps, 2001), Hollingworth et al. showed that whereas spatial attention forms a gradient across an attended object, the spread of this gradient is constrained by the boundaries of the object.

\section{Conclusion}

Since Duncan's (1984) seminal study, many advances have been made regarding the mechanisms that underlie the 
selection of visual attention. It is now generally accepted that attention selects the internal representation of both space and object, that space- and object-based attention interact, and that they are often evoked within the same visual scene. Object-based attention is frequently but not mandatorily deployed, and there are many factors that influence object segmentation. When object-based attention is deployed, it typically acts via the selection of an object's location, resulting in enhanced quality of the sensory representation of the selected object and more efficient processing of the features that belong to that object. It is important to recognize that although this tutorial emphasizes objectbased selection, attention can also select features and surfaces in addition to space. Our visual system uses different types of attention to give us a unified view of the world.

Author note I thank Kyle Cave, Morris Goldsmith, Pieter Roelfsema, and Jeremy Wolfe for their helpful comments on an earlier version of the manuscript.

\section{References}

Abrams, R. A., \& Law, M. B. (2000). Object-based visual attention with endogenous orienting. Perception \& Psychophysics, 62, 818-833.

Adelson, E. H., \& Bergen, J. R. (1991). The plenoptic function and the elements of early vision. In M. Landy \& J. A. Movshon (Eds.), Computational models of visual processing (pp. 3-20). Cambridge, MA: MIT Press.

Albrecht, A. R., List, A., \& Robertson, L. C. (2008). Attentional selection and the representation of holes and objects. Journal of Vision, 8, 1-10.

Ariga, A., Yokosawa, K., \& Ogawa, H. (2007). Object-based attentional selection and awareness of objects. Visual Cognition, 15, 685-709.

Arman, A. C., Ciaramitaro, V. M., \& Boynton, G. M. (2006). Effects of feature-based attention on the motion aftereffect at remote locations. Vision Research, 46, 2968-2976.

Arrington, C. M., Carr, T. H., Mayer, A. R., \& Rao, S. M. (2000). Neural mechanisms of visual attention: Object-based selection of a region in space. Journal of Cognitive Neuroscience, 12, 106-117.

Arrington, C. M., Dagenbach, D., McCartan, M. K., \& Carr, T. H. (2000, November). The reliability of object-based attention following peripheral and central cues. Poster presented at the 41st Annual Meeting of the Psychonomic Society, New Orleans, LA.

Avrahami, J. (1999). Objects of attention, objects of perception. Perception \& Psychophysics, 61, 1604-1612.

Awh, E., Dhaliwal, H., Christensen, S., \& Matsukura, M. (2001). Evidence for two components of object-based attention. Psychological Science, 12, 329-334.

Baker, C. I., Olson, C. R., \& Behrmann, M. (2004). Role of attention and perceptual grouping in visual statistical learning. Psychological Science, 15, 460-466.

Banks, W. P., \& Prinzmetal, W. (1976). Configurational effects in visual information processing. Perception \& Psychophysics, 19, 361-367.

Bao, M., Li, Z.-H., \& Zhang, D.-R. (2007). Binding facilitates attention switching within working memory. Journal of Experimental Psychology: Learning, Memory, and Cognition, 33, 959-969.
Baylis, G. C., \& Driver, J. (1992). Visual parsing and response competition: The effect of grouping factors. Perception \& Psychophysics, 51, 145-162.

Baylis, G. C., \& Driver, J. (1993). Visual attention and objects: Evidence for hierarchical coding of location. Journal of Experimental Psychology. Human Perception and Performance, 19, 451-470.

Baylis, G. C., Driver, J., \& McLeod, P. (1992). Movement and proximity constrain miscombinations of colour and form. Perception, $21,201-218$.

Behrmann, M., \& Moscovitch, M. (1994). Object-centered neglect in patients with unilateral neglect: Effects of left-right coordinates of objects. Journal of Cognitive Neuroscience, 6, 1-16.

Behrmann, M., Zemel, R. S., \& Mozer, M. C. (1998). Object-based attention and occlusion: Evidence from normal participants and a computational model. Journal of Experimental Psychology. Human Perception and Performance, 24, 1011-1036.

Bekkering, H., \& Pratt, J. (2004). Object-based processes in the planning of goal-directed hand movements. Quarterly Journal of Experimental Psychology, 57A, 1345-1368.

Berry, G., \& Klein, R. (1993). Does motion-induced grouping modulate the flanker compatibility effect? A failure to replicate Driver \& Baylis. Canadian Journal of Experimental Psychology, 47, 714-729.

Bisiach, E., \& Luzzatti, C. (1978). Unilateral neglect of representational space. Cortex, 14, 129-133.

Brown, J. M., \& Denney, H. I. (2007). Shifting attention into and out of objects: Evaluating the processes underlying the object advantage. Perception \& Psychophysics, 69, 606-618.

Caramazza, A., \& Hillis, A. E. (1990). Internal spatial representation of written words: Evidence from unilateral neglect. Nature, 346, 267-279.

Cave, K. R. (in press). Spatial attention. In D. Reisberg (Ed.), Oxford handbook of cognitive psychology. New York: Oxford University Press.

Cave, K. R., \& Bichot, N. P. (1999). Visuospatial attention: Beyond a spotlight model. Psychonomic Bulletin \& Review, 6, 204 223.

Cave, K. R., \& Pashler, H. (1995). Visual selection mediated by location: Selecting successive visual objects. Perception \& Psychophysics, 57, 421-432.

Chen, Z. (1998). Switching attention within and between objects: The role of subjective organization. Canadian Journal of Experimental Psychology, 52, 7-16.

Chen, Z. (2000). An object-based cost of visual filtering. Perception \& Psychophysics, 62, 482-495.

Chen, Z. (2009). Not all features are created equal: Processing asymmetries between location and object features. Vision Research, 49, 1481-1491.

Chen, Z., \& Cave, K. R. (2006). Reinstating object-based attention under positional certainty: The importance of subjective parsing. Perception \& Psychophysics, 68, 992-1003.

Chen, Z., \& Cave, K. R. (2008). Object-based attention with endogenous cuing and positional certainty. Perception \& Psychophysics, 70, 1435-1443.

Chong, S. C., \& Blake, R. (2006). Exogenous attention and endogenous attention influence initial dominance in binocular rivalry. Vision Research, 46, 1794-1803.

Chou, W.-L., \& Yeh, S.-L. (2008). Location- and object-based inhibition of return are affected by different kinds of working memory. Quarterly Journal of Experimental Psychology, 61, 1761-1768.

Crundall, D., Cole, G. G., \& Galpin, A. (2007). Object-based attention is mediated by collinearity of targets. Quarterly Journal of Experimental Psychology, 60, 137-153.

Dagenbach, D., Goolsby, B., Neely, C. A., \& Dadziak, K. M. (1997, November). Further studies of attention to space and objects with endogenous cueing. Poster presented at the 38th Annual Meeting of the Psychonomic Society, Philadelphia, PA. 
Desimone, R., \& Duncan, J. (1995). Neural mechanisms of selective visual attention. Annual Review of Neuroscience, 18, 193-222.

Di Lollo, V., Enns, J. T., \& Rensink, R. (2000). Competition for consciousness among visual events: The psychophysics of reentrant visual processes. Journal of Experimental Psychology. General, 129, 481-507.

Donnelly, N., Humphreys, G. W., \& Riddoch, M. J. (1991). Parallel computation of primitive shape descriptions. Journal of Experimental Psychology. Human Perception and Performance, 17, 561-570.

Downing, C. J., \& Pinker, S. (1985). The spatial structure of visual attention. In M. I. Posner \& O. S. M. Marin (Eds.), Attention and performance XI (pp. 171-187). Hillsdale, NJ: Erlbaum.

Driver, J., \& Baylis, G. C. (1989). Movement and visual attention: The spotlight metaphor breaks down. Journal of Experimental Psychology. Human Perception and Performance, 15, 448-456.

Driver, J., \& Baylis, G. C. (1998). Attention and visual object segmentation. In R. Parasuraman (Ed.), The attentive brain (pp. 299325). Cambridge, MA: MIT Press.

Driver, J., Baylis, G. C., \& Rafal, R. D. (1992). Preserved figureground segregation and symmetry perception in visual neglect. Nature, 360, 73-75.

Driver, J., \& Halligan, P. W. (1991). Can visual neglect operate in object-centred co-ordinates? An affirmative single-case study. Cognitive Neuropsychology, 8, 475-496.

Drummond, L., \& Shomstein, S. (2010). Object-based attention: Shifting or uncertainty? Attention, Perception, \& Psychophysics, 72, $1743-1755$.

Duncan, J. (1984). Selective attention and the organization of visual information. Journal of Experimental Psychology. General, 123, 501-517.

Duncan, J., \& Humphreys, G. (1989). Visual search and stimulus similarity. Psychological Review, 96, 433-458.

Duncan, J., \& Humphreys, G. (1992). Beyond the search surface: Visual search and attentional engagement. Journal of Experimental Psychology. Human Perception and Performance, 18, 578-588.

Egly, R., Driver, J., \& Rafal, R. D. (1994). Shifting visual attention between objects and locations: Evidence from normal and parietal lesion subjects. Journal of Experimental Psychology. General, 123, 161-177.

Egly, R., Rafal, R., Driver, J., \& Starreveld, Y. (1994). Hemispheric specialization for object-based attention in a split brain patient. Psychological Science, 5, 380-383.

Eriksen, B. A., \& Eriksen, C. W. (1974). Effects of noise letters upon the identification of target letter in a nonsearch task. Perception \& Psychophysics, 16, 143-149.

Eriksen, C. W., \& Murphy, T. D. (1987). Movement of attentional focus across the visual field: A critical look at the evidence. Perception \& Psychophysics, 42, 299-305.

Eriksen, C. W., \& St. James, J. (1986). Visual attention within and around the field of focal attention: A zoom lens model. Perception \& Psychophysics, 40, 225-240.

Farah, M. J., Brunn, J. L., Wong, A. B., Wallace, M. A., \& Carpenter, P. (1990). Frames of reference for allocating attention to space: Evidence from the neglect syndrome. Neuropsychologia, 28, 335-347.

Fischer, M. H., \& Hoellen, N. (2004). Space- and object-based attention depend on motor intention. The Journal of General Psychology, 131, 365-377.

Francolini, C. M., \& Egeth, H. A. (1980). On the nonautomaticity of "automatic" activation: Evidence of selective seeing. Perception \& Psychophysics, 27, 331-342.

Franconeri, S. L., Hollingworth, A., \& Simons, D. J. (2005). Do new objects capture attention? Psychological Science, 16, 275-281.

Fuentes, L. J., Humphreys, G. W., Agis, I. F., Carmona, E., \& Catena, A. (1998). Object-based perceptual grouping affects negative priming. Journal of Experimental Psychology. Human Perception and Performance, 24, 664-672.
Gibson, B. S., \& Egeth, H. (1994). Inhibition of return to object-based and environment-based locations. Perception \& Psychophysics, $55,323-339$.

Goldsmith, M. (1998). What's in a location? Comparing objectbased and space-based models of feature integration in visual search. Journal of Experimental Psychology. General, 127, 189-219.

Goldsmith, M., \& Yeari, M. (2003). Modulation of object-based attention by spatial focus under endogenous and exogenous orienting. Journal of Experimental Psychology. Human Perception and Performance, 29, 897-918.

Harms, L., \& Bundesen, C. (1983). Color segregation and selective attention. Perception \& Psychophysics, 33, 11-19.

He, X., Fan, S., Zhou, K., \& Chen, L. (2004). Cue validity and objectbased attention. Journal of Cognitive Neuroscience, 16, 10851097.

He, X., Humphreys, G., Fan, S., Chen, L., \& Han, S. (2008). Differentiating spatial and object-based effects on attention: an eventrelated brain potential study with peripheral cueing. Brain Research, 1245, 116-125.

He, Z. J., \& Nakayama, K. (1995). Visual attention to surfaces in threedimensional space. Proceedings of the National Academy of Sciences, 92, 11155-11159.

Hecht, L. N., \& Vecera, S. P. (2007). Attentional selection of surface uniformity and part structure. Psychonomic Bulletin \& Review, 14, 1205-1211.

Hillyard, S. A., Anllo-Vento, L., Clark, V., Henze, H., Luck, S., \& Mangun, G. (1996). Neuroimaging approaches to the study of visual attention: A tutorial. In A. F. Kramer, M. G. Coles, \& G. D. Logan (Eds.), Converging operations in the study of visual selective attention (pp. 107-138). Washington, DC: APA Press.

Ho, M.-C., \& Atchley, P. (2009). Perceptual load modulates objectbased attention. Journal of Experimental Psychology. Human Perception and Performance, 35, 1661-1669.

Hochstein, S., \& Ahissar, M. (2002). View from the top: Hierarchies and reverse hierarchies in the visual system. Neuron, 36, 791804.

Hoffman, J. E., \& Nelson, B. (1981). Spatial selectivity in visual search. Perception \& Psychophysics, 30, 283-290.

Hollingworth, A., Maxcey-Richard, A. M., \& Vecera, S. P. (2012). The spatial distribution of attention within and across objects. Journal of Experimental Psychology. Human Perception and Performance, 38, 135-151.

Hoover, M. A., \& Richardson, D. C. (2008). When facts go down the rabbit hole: Contrasting features and objecthood as indexes to memory. Cognition, 108, 533-542.

Houtkamp, R., Spekreijse, H., \& Roelfsema, P. R. (2003). A gradual spread of attention during mental curve tracing. Perception \& Psychophysics, 65, 1136-1144.

Humphreys, G. W., Quinlan, P. T., \& Riddoch, M. J. (1989). Grouping processes in visual search: Effects with single- and combinedfeature targets. Journal of Experimental Psychology. General, $118,258-279$.

Humphreys, G. W., \& Riddoch, M. J. (1993). Interactions between object and space-systems revealed through neuropsychology. In D. E. Meyer \& S. S. Kornblum (Eds.), Attention and performance XIV (pp. 143-162). Cambridge, MA: MIT Press.

Humphreys, G. W., \& Riddoch, M. J. (2003). From what to where: Neuropsychological evidence for implicit interactions between object- and space-based attention. Psychological Science, 14, 487-492.

Humphreys, G. W., Romani, C., Olson, A., Riddoch, M., \& Duncan, J. (1994). Nonspatial extinction following lesions of the parietal lobes in humans. Nature, 372, 357-359.

Jordan, H., \& Tipper, S. P. (1998). Object-based inhibition of return in static displays. Psychonomic Bulletin \& Review, 5, 504-509. 
Jordan, H., \& Tipper, S. P. (1999). Spread of inhibition across an object's surface. British Journal of Psychology, 90, 495-507.

Kahneman, D., \& Chajczyk, D. (1983). Tests of the automaticity of reading: Dilution of Stroop effects by color-irrelevant stimuli. Journal of Experimental Psychology. Human Perception and Performance, 9, 497-509.

Kahneman, D., \& Henik, A. (1977). Effects of visual grouping on immediate recall and selective attention. In S. Dornic (Ed.), Attention and performance VI (pp. 307-332). Hillsdale, NJ: Erlbaum.

Kahneman, D., \& Henik, A. (1981). Perceptual organization and attention. In M. Kubovy \& J. R. Pomerantz (Eds.), Perceptual organization (pp. 181-211). Hillsdale, NJ: Erlbaum.

Kahneman, D., \& Treisman, A. (1984). Changing views of attention and automaticity. In R. Parasuraman \& D. A. Davies (Eds.), Varieties of attention (pp. 29-61). New York: Academic Press.

Kahneman, D., Treisman, A., \& Burkell, J. (1983). The cost of visual filtering. Journal of Experimental Psychology. Human Perception and Performance, 9, 510-522.

Kahneman, D., Treisman, A., \& Gibbs, B. J. (1992). The reviewing of object files: Object-specific integration of information. Cognitive Psychology, 24, 175-219.

Kanwisher, N., \& Driver, J. (1992). Objects, attributes, and visual attention: Which, what, and where. Current Directions in Psychological Science, 1, 26-31.

Kim, M.-S., \& Cave, K. R. (1995). Spatial attention in visual search for features and feature conjunctions. Psychological Science, 6, 376-380.

Kim, M.-S., \& Cave, K. R. (2001). Perceptual grouping via spatial selection in a focused-attention task. Vision Research, 41, 611624.

Kimchi, R., Yeshurun, Y., \& Cohen-Savransky, A. (2007). Automatic, stimulus-driven attentional capture by objecthood. Psychonomic Bulletin \& Review, 14, 166-172.

Klein, R. (1988). Inhibitory tagging system facilitates visual search. Nature, 334, 430-431.

Kramer, A. F., \& Jacobson, A. (1991). Perceptual organization and focused attention: The role of objects and proximity in visual processing. Perception \& Psychophysics, 50, 267-284.

Kramer, A. F., Tham, M. P., \& Yeh, Y. Y. (1991). Movement and focused attention: A failure to replicate. Perception \& Psychophysics, 50, 537-546.

Kramer, A. F., \& Watson, S. E. (1996). Object-based visual selection and the principle of uniform connectedness. In A. F. Kramer, M. G. H. Coles, \& G. D. Logan (Eds.), Converging operations in the study of visual selective attention (pp. 395-414). Washington, DC: American Psychological Association.

Kramer, A. F., Weber, T. A., \& Watson, S. E. (1997). Object-based attentional selection: Grouped arrays or spatially invariant representations? Comment on Vecera and Farah (1994). Journal of Experimental Psychology. General, 126, 3-13.

LaBerge, D. (1983). Spatial extent of attention to letters in words. Journal of Experimental Psychology. Human Perception and Performance, 9, 371-379.

Lamy, D. (2000). Object-based selection under focused attention: A failure to replicate. Perception \& Psychophysics, 62, 1272-1279.

Lamy, D., \& Egeth, H. (2002). Object-based selection: The role of attentional shifts. Perception \& Psychophysics, 64, 52-66.

Lamy, D., \& Tsal, Y. (2000). Object features, object locations, and object files: Which does selective attention activate and when? Journal of Experimental Psychology. Human Perception and Performance, 26, 1387-1400.

Lamy, D., \& Tsal, Y. (2001). On the status of location in visual attention. European Journal of Cognitive Psychology, 13, 305-342.

Lauwereyns, J. (1998). Exogenous/endogenous control of space-based/ object-based attention: Four types of visual selection. European Journal of Cognitive Psychology, 10, 41-74.
Lavie, N., \& Driver, J. (1996). On the spatial extent of attention in object-based visual selection. Perception \& Psychophysics, 58, $1238-1251$.

Law, M. B., \& Abrams, R. A. (2002). Object-based selection with and beyond the focus of spatial attention. Perception \& Psychophysics, 64, 1017-1027.

Li, X., \& Logan, G. D. (2008). Object-based attention in Chinese readers of Chinese words: Beyond Gestalt principles. Psychonomic Bulletin \& Review, 15, 945-949.

Linnell, K. J., Humphreys, G. W., McIntyre, D. B., Laitinen, S., \& Wing, A. M. (2005). Action modulates object-based selection. Vision Research, 45, 2268-2286.

List, A., \& Robertson, L. C. (2007). Inhibition of return and objectbased attentional selection. Journal of Experimental Psychology. Human Perception and Performance, 33, 1322-1334.

Liu, T., Larsson, J., \& Carrasco, M. (2007). Feature-based attention modulates orientation-selective responses in human visual cortex. Neuron, 55, 313-323.

Logan, G. (1996). The CODE theory of visual attention: An integration of space-based and object-based attention. Psychological Review, 103, 603-649.

Luck, S. J., Heinze, H. J., Mangun, G. R., \& Hillyard, S. A. (1990). Visual event-related potential index of focused attention within bilateral stimulus array: II. Functional dissociation of P1 and N1 components. Electroencephalography \& Clinical Neurophysiology, $75,528-542$.

Macquistan, A. (1997). Object based allocation of visual attention in response to exogenous, but not endogenous, spatial precues. Psychonomic Bulletin \& Review, 4, 512-515.

Marino, A. C., \& Scholl, B. J. (2005). The role of closure in defining the "objects" of object-based attention. Perception \& Psychophysics, 67, 1140-1149.

Marr, D. (1982). Vision. New York: Freeman.

Marshall, J. C., \& Halligan, P. W. (1994). The yin and yang of visuospatial neglect: A case study. Neuropsychologia, 32, 1037-1057.

Martínez, A., Teder-Sälejärvi, W., \& Hillyard, S. A. (2007). Spatial attention facilitates selection of illusory objects: Evidence from event-related brain potentials. Brain Research, 1139, 143-152.

Martínez, A., Teder-Sälejärvi, W., Vazquez, M., Molholm, S., Foxe, J. J., Javitt, D. C., ... Hillyard, S. A. (2006). Objects are highlighted by spatial attention. Journal of Cognitive Neuroscience, 18, 298310.

Martínez-Trujillo, J. C., \& Treue, S. (2004). Feature-based attention increases the selectivity of population responses in primate visual cortex. Current Biology, 14, 744-751.

Matsukura, M., \& Vecera, S. P. (2006). The return of object-based attention: Selection of multiple-region objects. Perception \& Psychophysics, 68, 1163-1175.

Matsukura, M., \& Vecera, S. P. (2011). Object-based selection from spatially-invariant representations: Evidence from a feature-report task. Attention, Perception, \& Psychophysics, 73, 447-457.

Mattingley, J. B., Davis, G., \& Driver, J. (1997). Preattentive filling-in of visual surface in parietal extinction. Science, 275, 671-674.

Maunsell, J. H. R., \& Treue, S. (2006). Feature-based attention in visual cortex. Trends in Neurosciences, 29, 317-322.

McCarley, J., Kramer, A. F., \& Peterson, M. S. (2002). Overt and covert object-based attention. Psychonomic Bulletin \& Review, 9, 751-758.

McCrae, C. S., \& Abrams, R. A. (2001). Age-related differences in object- and location-based inhibition of return of attention. Psychology and Aging, 16, 437-449.

Mitchell, J. F., Stoner, G. R., \& Reynolds, J. H. (2004). Object-based attention determines dominance in binocular rivalry. Nature, 429, $410-413$.

Mitroff, S. R., \& Scholl, B. J. (2005). Forming and updating object representations without awareness: Evidence from motioninduced blindness. Vision Research, 45, 961-967. 
Moore, C. M., Yantis, S., \& Vaughan, B. (1998). Object-based visual attention: Evidence from perceptual completion. Psychological Science, 9, 104-110.

Müller, N. G., \& Kleinschmidt, A. (2003). Dynamic interaction of object- and space-based attention in retinotopic visual areas. Journal of Neuroscience, 23, 9812-9816.

Neely, C. A., \& Dagenbach, D. (1996, November). Exogenous and endogenous cuing: Spatial versus object-based visual attention. Poster presented at the 37th Annual Meeting of the Psychonomic Society, Chicago, IL.

Neisser, U., \& Becklen, R. (1975). Selective looking: Attending to visually specified events. Cognitive Psychology, 7, 480-494.

Newell, F. N., Brown, V., \& Findlay, J. M. (2004). Is object search mediated by object-based or image-based representations? Spatial Vision, 17, 511-541.

O'Craven, K. M., Downing, P. E., \& Kanwisher, N. (1999). fMRI evidence for objects as the units of attentional selection. Nature, $401,584-587$.

O'Grady, R. B., \& Müller, H. J. (2000). Object-based selection operates on a grouped array of locations. Perception \& Psychophysics, $62,1655-1667$.

Ohyama, J., \& Watanabe, K. (2010). Exogenous temporal cues enhance recognition memory in an object-based manner. Attention, Perception, \& Psychophysics, 72, 2157-2167.

Posner, M. I. (1980). Orienting of attention. Quarterly Journal of Experimental Psychology, 32, 3-25.

Posner, M. I., \& Cohen, Y. (1984). Components of visual orienting. In H. Bouma \& D. G. Bowhuis (Eds.), Attention and performance $X$ (pp. 531-556). Hillsdale, NJ: Erlbaum.

Posner, M. I., \& Peterson, S. E. (1990). The attention system of the human brain. Annual Review of Neuroscience, 13, 25-42.

Posner, M. I., Snyder, C. R. R., \& Davidson, B. J. (1980). Attention and the detection of signals. Journal of Experimental Psychology. General, 109, 106-174.

Pratt, J., \& Sekuler, A. B. (2001). The effects of occlusion and past experience on the allocation of object-based attention. Psychonomic Bulletin \& Review, 8, 721-727.

Prinzmetal, W., \& Keysar, B. (1989). Functional theory of illusory conjunctions and neon colors. Journal of Experimental Psychology. General, 118, 165-190.

Pylyshyn, Z. W., \& Storm, R. W. (1988). Tracking multiple independent targets: Evidence for a parallel tracking mechanism. Spatial Vision, 3, 179-197.

Rensink, R. A., \& Enns, J. T. (1995). Preemption effects in visual search: Evidence for low-level grouping. Psychological Review, 102, 101-130.

Richard, A. M., Lee, H., \& Vecera, S. P. (2008). Attentional spreading in object-based attention. Journal of Experimental Psychology. Human Perception and Performance, 34, 842-853.

Roelfsema, P. R., \& Houtkamp, R. (2011). Incremental grouping of image elements in vision. Attention, Perception, \& Psychophysics, 73, 2542-2572.

Roelfsema, P. R., Khayat, P. S., \& Spekreijse, H. (2003). Subtask sequencing in the primary visual cortex. Proceedings of the $\mathrm{Na}$ tional Academy of Sciences, 100, 5467-5472.

Roelfsema, P. R., Lamme, V. A. F., \& Spekreijse, H. (1998). Objectbased attention in the primary visual cortex of the macaque monkey. Nature, 395, 376-381.

Rossi, A. F., \& Paradiso, M. A. (1995). Feature-specific effects of selective visual attention. Vision Research, 35, 621-634.

Sàenz, M., Buračas, G. T., \& Boynton, G. M. (2002). Global effects of feature-based attention in human visual cortex. Nature Neuroscience, 5, 631-632.

Sàenz, M., Buračas, G. T., \& Boynton, G. M. (2003). Global featurebased attention for motion and color. Vision Research, 43, 629637.
Saiki, J. (2000). Occlusion, symmetry, and object-based attention: Comment on Behrmann, Zemel, and Mozer (1998). Journal of Experimental Psychology. Human Perception and Performance, 26, 424-433.

Scholl, B. J. (2001). Objects and attention: The state of the art. Cognition, 80, 1- 46.

Scholl, B. J., Pylyshyn, Z. W., \& Feldman, J. (2001). What is a visual object? Evidence from target merging in multiple object tracking. Cognition, 80, 159-177.

Shomstein, S., \& Behrmann, M. (2008). Object-based attention: Strength of object representation and attentional guidance. Perception \& Psychophysics, 70, 132-144.

Shomstein, S., \& Yantis, S. (2002). Object-based attention: Sensory modulation or priority setting? Perception \& Psychophysics, 64, $41-51$.

Shomstein, S., \& Yantis, S. (2004). Configural and contextual prioritization in object-based attention. Psychonomic Bulletin \& Review, 11, 247-253.

Shulman, G. L., \& Wilson, J. (1987). Spatial frequency and selective attention to local and global information. Perception, 16, 89-101.

Spivey, M. J., \& Spirn, M. J. (2000). Selective visual attention modulates the direct tilt aftereffect. Perception \& Psychophysics, 62, $1525-1533$.

Theeuwes, J., \& Mathot, S. (2010). Object-based eye movements: The eyes prefer to stay within the same object. Attention, Perception, \& Psychophysics, 72, 597-601.

Tipper, S. P. (1985). The negative priming effect: Inhibitory effects of ignored primes. Quarterly Journal of Experimental Psychology, $37 A, 571-590$.

Tipper, S. P., Brehaut, J. C., \& Driver, J. (1990). Selection of moving and static objects for the control of spatially directed action. Journal of Experimental Psychology. Human Perception and Performance, 16, 492-504.

Tipper, S. P., Driver, J., \& Weaver, B. (1991). Object-centred inhibition of return of visual attention. Quarterly Journal of Experimental Psychology, 43A, 289-298.

Tipper, S. P., Weaver, B., Jerreat, L. M., \& Burak, A. L. (1994). Objectbased and environment-based inhibition of return of visual attention. Journal of Experimental Psychology. Human Perception and Performance, 20, 478-499.

Treisman, A. (1982). Perceptual grouping and attention in visual search for features and for objects. Journal of Experimental Psychology. Human Perception and Performance, 8, 194-214.

Treue, S., \& Martínez-Trujillo, J. C. (1999). Feature-based attention influences motion processing gain in macaque visual cortex. Nature, 399, 575-579.

Tsal, Y., \& Lavie, N. (1993). Location dominance in attending to color and shape. Journal of Experimental Psychology. Human Perception and Performance, 19, 131-139.

Valdes-Sosa, M., Bobes, M. A., Rodriguez, V., \& Pinilla, T. (1998). Switching attention without shifting the spotlight: Object-based attentional modulation of brain potentials. Journal of Cognitive Neuroscience, 10, 137-151.

van der Velde, F., \& de Kamps, M. (2001). From knowing what to knowing where: Modelling object-based attention with feedback disinhibition of activation. Journal of Cognitive Neuroscience, 13, 479-491.

Vecera, S. P. (1994). Grouped locations and object-based attention: Comment on Egly, Driver, and Rafal (1994). Journal of Experimental Psychology. General, 123, 316-320.

Vecera, S. P. (1997). Grouped arrays versus object-based representations: Reply to Kramer et al. (1997). Journal of Experimental Psychology: General, 126, 14-18.

Vecera, S. P., \& Farah, M. J. (1994). Does visual attention select objects or locations? Journal of Experimental Psychology. General, 123, 146-160. 
Wannig, A., Rodríguez, V., \& Freiwald, W. A. (2007). Attention to surfaces modulates motion processing in extrastriate area MT. Neuron, 54, 639-651.

Wannig, A., Stanisor, L., \& Roelfsema, P. R. (2011). Automatic spread of attentional response modulation along Gestalt criteria in primary visual cortex. Nature Neuroscience, 14, 1243-1244.

Ward, R., Goodrich, S., \& Driver, J. (1994). Grouping reduces visual extinction. Visual Cognition, 1, 101-129.

Watson, S. E., \& Kramer, A. F. (1999). Object-based visual selective attention and perceptual organization. Perception \& Psychophysics, 61, 31-49.

Watt, R. (1988). Visual processing: Computational, psychophysical and cognitive research. London: Erlbaum.

Weber, T. A., Kramer, A. F., \& Miller, A. G. (1997). Selective processing of superimposed objects: An electrophysiological analysis of objectbased attentional selection. Biological Psychology, 45, 159-182.

White, A. L., \& Carrasco, M. (2011). Feature-based attention involuntarily and simultaneously improves visual performance across locations. Journal of Vision, 11, 1-10.
Wolfe, J. M., \& Bennett, S. C. (1997). Preattentive object files: Shapeless bundles of basic features. Vision Research, 37, 25-43.

Yantis, S. (1988). On analog movements of attention. Perception \& Psychophysics, 43, 203-206.

Yantis, S., \& Hillstrom, A. P. (1994). Stimulus-driven attentional capture: Evidence form equiluminant visual objects. Journal of Experimental Psychology. Human Perception and Performance, 20, 95-107.

Yantis, S., \& Jonides, J. (1996). Attentional capture by abrupt onsets: New perceptual objects or visual masking. Journal of Experimental Psychology. Human Perception and Performance, 22, 1505-1513.

Yeari, M., \& Goldsmith, M. (2010). Is object-based attention mandatory? Strategic control over mode of attention. Journal of Experimental Psychology. Human Perception and Performance, 36, 565-579.

Yeshurun, Y., Kimchi, R., Sha'shoua, G., \& Carmel, T. (2009). Perceptual objects capture attention. Vision Research, 49, 1329-1335.

Young, A. W., Hellawell, D. J., \& Welch, J. (1992). Neglect and visual recognition. Brain, 115, 51-71. 